\title{
FBXO31 is down-regulated and may function as a tumor suppressor in hepatocellular carcinoma
}

\author{
HAI-LI HUANG, WEN-LING ZHENG, RUI ZHAO, BAO ZHANG and WEN-LI MA \\ Institute of Molecular Biology, Southern Medical University, Guangzhou 510515, P.R. China
}

Received April 3, 2010; Accepted June 2, 2010

DOI: $10.3892 /$ or_00000912

\begin{abstract}
The F-box protein family member FBXO31 has rarely been studied in human hepatocellular carcinoma (HCC). This study was designed to investigate the expression profile of FBXO31 in HCC and the possibility that FBXO31 might function as a tumor suppressor in HCC cell lines. We report that FBXO31 is strongly down-regulated in HCC cell lines and specimens. Ectopic expression of FBXO31 inhibited cell proliferation and colony formation in HepG2 and Hep3B cells. The endogenous expression of FBXO31 was fluctuated through cell cycle in the HepG2 cells with maximal expression from late G2 to early G1 phase. Ectopic expression of FBXO31 in HepG2 resulted in the accumulation of cells at the $\mathrm{G} 1$ phase of the cell cycle. Possible mechanism might be cyclin D1 degradation mediate by FBXO31 through ubiquitin ligase pathway. Ectopic overexpression of FBXO31 resulted in down-regulation of cyclin D1 which leads to the accumulation of cells at the G1 phase of the cell cycle. Cytoplasmic location of FBXO31 was consistent with cyclin D1 degradation in cytoplasm. Together, our findings suggested that down-regulation of FBXO31 might function as a tumor suppressor in HCC.
\end{abstract}

\section{Introduction}

The F-box family is known to take part in degradation of proteins through ubiquitin-mediated proteolysis by involvement in the formation of SCF ubiquitin ligase complexes, which are involved in diverse cellular functions, including signal transduction, control of G1-S progression, and orderly execution of the cell cycle (1-4). There are currently three subdivisions of the F-box protein family based on the type of carboxy-terminal motifs present in the protein sequences. F-boxes that contain LRRs defined as FBXL, those con-taining WD repeats as FBXW, and those

Correspondence to: Dr Wen-Li Ma, Institute of Molecular Biology, Southern Medical University, Guangzhou 510515, P.R. China

E-mail: wenlima1964@yahoo.com.cn

Key words: FBXO31, down-regulation, hepatocellular carcinoma lacking all known protein-interaction domains as FBXO. FBXO31 belongs to the FBXO class (5-8).

Previous study demonstrated that FBXO31 was the chromosome 16q24.3 senescence gene and candidate breast tumor suppressor (9). FBXO31 could mediate cyclin D1 degradation to induce G1 arrest after DNA damage (10). Quantitative gene expression analysis of 78 genes in the $16 q 24.3$ region demonstrated that FBXO31 was one of two genes including CYBA2T3 with a moderately aberrant expression profile. Expression of FBXO31 was reduced 100 to 200-fold in MDA-MB-134 and SK-BR-3 and moderately reduced in the other cell lines. Microarray analysis indicated FBXO31 was one of the 70-gene classifiers down-regulated in association with tumors of a favorable prognosis $(11,12)$. With regard to hepatocellular carcinoma (HCC), the fifth most common cancer worldwide and the third most common cause of cancer mortality, the expression profile and function of FBXO31 is still obscure. In this study, we investigated the expression profile of FBXO31 gene in $\mathrm{HCC}$ and the possibility that FBXO31 might function as a tumor suppressor in HCC cell lines.

\section{Materials and methods}

Tissue specimens and cell lines. All specimens were harvested from patients who suffered from HCC with informed consent. Ten liver tumor-derived cell lines and the fetal liver-derived cell line L02 were used in this study. Patient material was obtained on approval of local medical ethics committees.

Quantitative and real-time reverse transcription-PCR. FBXO31 expression was determined by real-time quantitative reverse transcription-PCR (RT-PCR) with the forward primer: 5'-CCGGCGGGAGGCAGGAGGAGT-3' and reverse primer: 5'-GCGGCGGTAGGTCAGGCAGTTG TCG-3'. B-actin served as a loading control.

Plasmids. FBXO31 open reading frame (ORF) was PCR amplified from FBXO31 cDNA clone (Open Biosystem) and inserted into the pcDNA3.1-myc-his (Invitrogen) to generate clones expressing myc-FBXO31 protein. FBXO31 coding fragments were cloned in-frame with the enhanced green fluorescent protein (EGFP) ORF into pEGFP-C1 (BD Biosciences) to generate constructs capable of expressing EGFP- FBXO31 protein. myc-FBXO31 and EGFP-FBXO31 were used to generate stable FBXO31 expressing cell lines 
$\mathbf{A}$

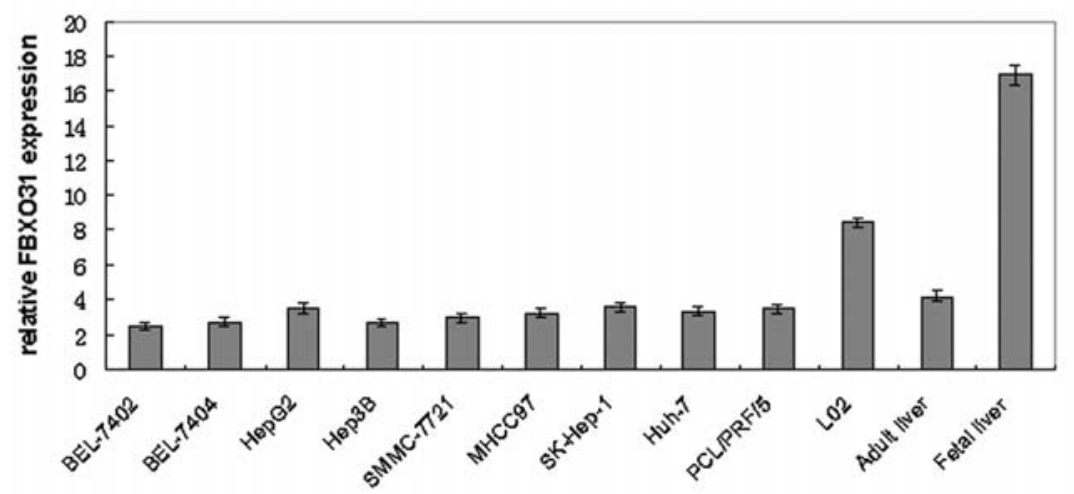

B

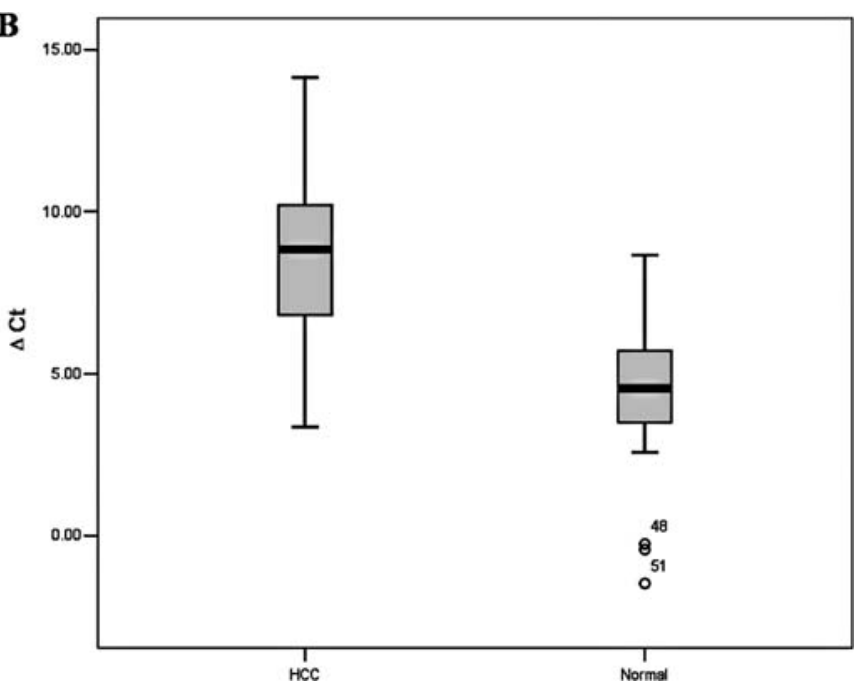

according to the manufacturer's instructions. The sequences of all constructs were confirmed by DNA sequencing.

Cell transfection. Cell transfection was performed by Lipofectamine 2000 (Invitrogen) according to the manufacturer's instructions.

Cell proliferation and colony formation. Proliferation assays were determined on EGFP-FBXO31 transfected cells selected for 10 to 14 days in the presence of G418. These cells were plated at $10-20 \%$ confluence in 96-well plates and at various times samples $(n=6-8)$. Cell viability was measured using the Cell Titer-Blue ${ }^{\mathrm{TM}}$ Cell Viabiliy Assay (Promega) according to the manufacturer's instructions.

HCC cells transfected by EGFP-FBXO31 were cultured on a $10-\mathrm{cm}$ plate for colony formation with the presence of G418 at a final concentration of $0.6-1 \mathrm{mg} / \mathrm{ml}$ and colonies were counted in triplicate wells after growth for a further 2-3 weeks. The empty vector was used as a negative control.

Cell synchronization. Cells were synchronized at G1-S phase using a double thymidine block. Cells were grown in the presence of $2 \mathrm{mmol} / \mathrm{l}$ thymidine (Sigma-Aldrich) for $24 \mathrm{~h}$ and then washed and grown in fresh medium without thymidine for $10 \mathrm{~h}$. Cells were cultured in the presence of $2 \mathrm{mmol} / \mathrm{l}$ thymidine for a further $16 \mathrm{~h}$ and then released from the G1-S block by washing twice with fresh medium. Cells collected at various time points following release from the
Figure 1. Expression pattern of FBXO31 in HCC cell lines and specimens. (A) Relative mRNA level of FBXO31 was evaluated in HCC cell lines and fetal and adult human livers by quantitative RT-PCR, where B-actin was used as internal reference. (B) The transcript level of FBXO31 was measured in $32 \mathrm{HCC}$ specimens and corresponding adjacent healthy livers by quantitative real-time RT-PCR, where $\beta$-actin was used as internal reference.

second thymidine block were lysed in $50 \mathrm{mmol} / \mathrm{l}$ Tris- $\mathrm{HCl}$ (pH 7.5), $250 \mathrm{mmol} / \mathrm{l}$.

$\mathrm{NaCl}, 1 \%$ Triton $\mathrm{X}-100,1 \mathrm{mmol} / \mathrm{l}$ EDTA, $50 \mathrm{mmol} / \mathrm{l} \mathrm{NaF}$, $0.1 \mathrm{mmol} / 1 \mathrm{Na} 3 \mathrm{VO} 4,1 \mathrm{mmol} / 1 \mathrm{DTT}$, protease inhibitors (Sigma) on ice for $15 \mathrm{~min}$. Lysed samples were clarified by centrifugation and then assayed for protein concentration using bicinchoninic acid protein assay reagent kit (Pierce).

Cell cycle analysis. HCC cells were transfected with pEGFP-FBXO31 or pEGFP-C1 using Lipofectamine 2000 (Invitrogen). Cells were collected 24 and $48 \mathrm{~h}$ after transfection and treated as described (13). Briefly, cells were pelleted (400 x g for $5 \mathrm{~min}$ at $4^{\circ} \mathrm{C}$ ), washed twice with cold PBS, resuspended in $500 \mu \mathrm{l}$ of cold PBS, and then fixed for $1 \mathrm{~h}$ at $4^{\circ} \mathrm{C}$ by adding $500 \mu \mathrm{l}$ of fixation solution $(2 \% \mathrm{w} / \mathrm{v}$ paraformaldehyde in PBS, $\mathrm{pH}$ 7.2). The fixed cells were pelleted, washed with cold PBS, resuspended in $1 \mathrm{ml}$ of $70 \%$ ethanol added dropwise to the pellet while vortexing, and then incubated overnight at $4^{\circ} \mathrm{C}$. The next day, the cells were pelleted and resuspended in $1 \mathrm{ml}$ propidium iodide solution (40 $\mu \mathrm{g} / \mathrm{ml}$ with $100 \mu \mathrm{g} / \mathrm{ml}$ RNase A) for $30 \mathrm{~min}$ at $37^{\circ} \mathrm{C}$ in the dark and analyzed on a FACScan flow cytometer (BD Biosciences).

Western blot analysis. Western blot analysis was performed according to the manufacturer's recommended protocol (Santa Cruz Biotechnology), B-actin served as a loading control. Briefly, cell extracts were prepared in lysis buffer $[25 \mathrm{mmol} / \mathrm{l}$ 
A

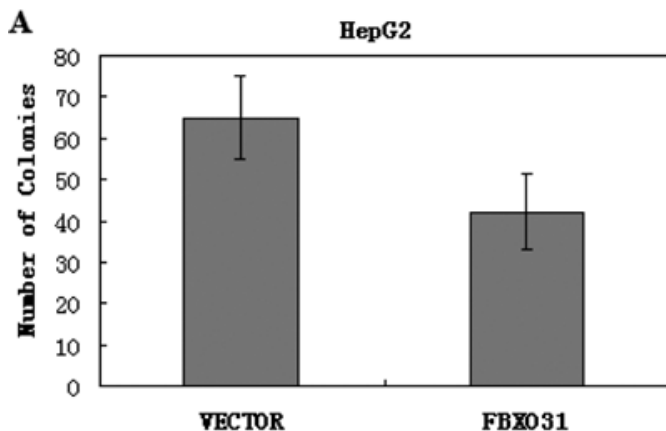

C

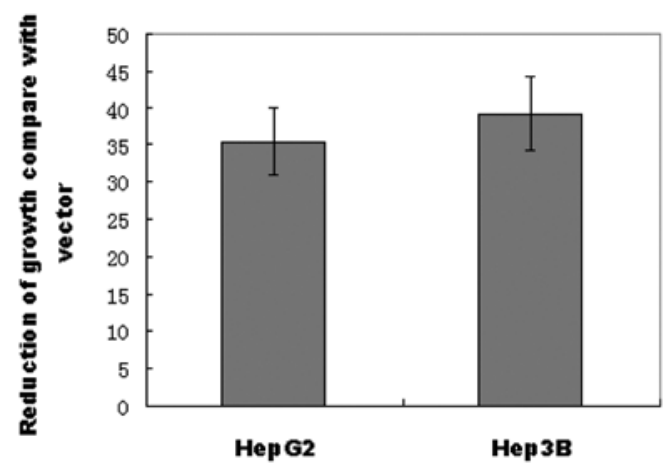

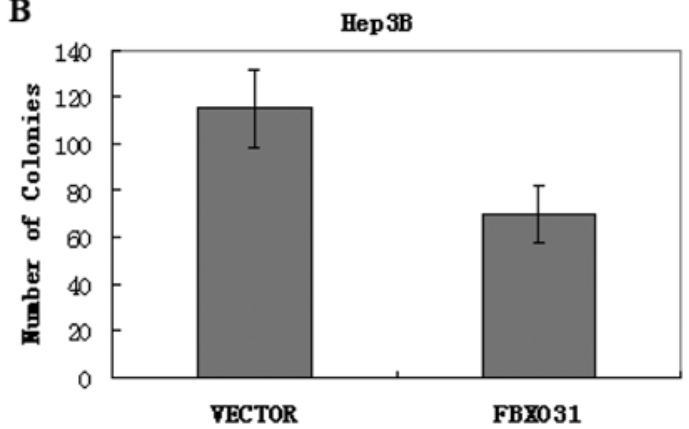

D

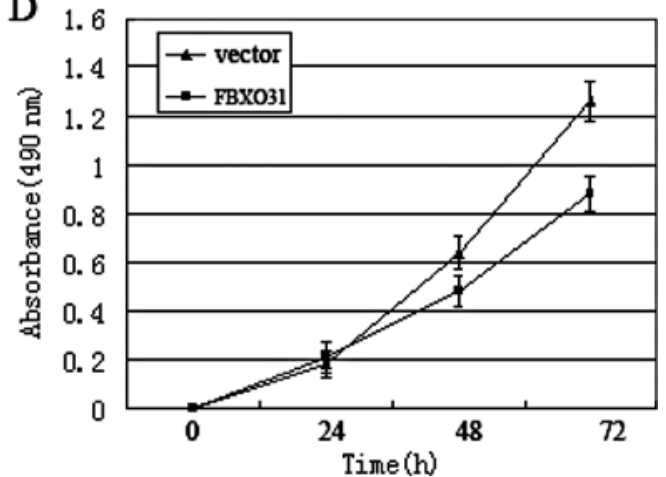

Figure 2. Ectopic expression of FBXO31 reduced the growth characteristics of the HCC cell lines HepG2 and Hep3B. The HepG2 (A) and Hep3B (B) HCC cell lines were transfected with EGFP-FBXO31 and empty vector (negative control). Number of colonies growing on plastic dishes in the presence of G418, 2 weeks after transfection was counted. (C) Average effect of ectopic expression of EGFP-FBXO31 on colony growth, compared with vector alone, from four independent experiments with HepG2 and Hep3B. (D) EGFP-FBXO31 ectopic expression inhibited HepG2 cell growth. Growth assays were initiated from cultures transfected with EGFP-FBXO31 and empty vector and selected for 14 days in media containing G418.

Tris ( $\mathrm{pH} 6.8), 1 \% \mathrm{SDS}, 5 \mathrm{mmol} / \mathrm{l}$ EDTA, protease inhibitor cocktail (Sigma)]. The blot is incubated with blocking solution (5\% nonfat milk and $0.1 \%$ Tween-20 in PBS) for $2 \mathrm{~h}$ at room temperature. Cyclin B1 (Santa Cruz Biotechnology), cyclin D1 (Santa Cruz Biotechnology) and FBXO31 antibodies were used in this study. The rabbit polyclonal antibody, raised against FBXO31 protein, was produced as previously described (10).

Subcellular fractionation. Cells were collected by centrifugation at $300 \mathrm{x} \mathrm{g}$ for $4 \mathrm{~min}$ at $4^{\circ} \mathrm{C}$ and suspended in $400 \mathrm{ml}$ buffer A [10 mM HEPES (pH 7.5), 10 mM KCl, 1 mM DTT, $1 \mathrm{mM}$ PMSF, $20 \mathrm{U} / \mathrm{ml}$ aprotinin, $5 \mathrm{mg} / \mathrm{ml}$ leupeptin, $0.4 \mathrm{mM}$ $\mathrm{NaF}$, and $10 \mathrm{mM}$ B-glycerophosphate]. After incubation on ice for $15 \mathrm{~min}, 12.5 \mathrm{ml}$ of $10 \% \mathrm{NP}-40$ was added and incubated on ice for $10 \mathrm{~min}$. Nuclei were pelleted at $1500 \mathrm{x} \mathrm{g}$ for $5 \mathrm{~min}$, and the supernatant (cytoplasmic extracts) was centrifuged at $13,000 \times \mathrm{g}$. Nuclei were washed with $1 \mathrm{ml}$ of buffer A twice and suspended in $50 \mathrm{ml}$ of buffer B [20 mM HEPES ( $\mathrm{pH} 7.5)$, $0.4 \mathrm{M} \mathrm{NaCl}, 1 \mathrm{mM}$ DTT, $1 \mathrm{mM}$ PMSF, $20 \mathrm{U} / \mathrm{ml}$ aprotinin, $5 \mathrm{mg} / \mathrm{ml}$ leupeptin, $0.4 \mathrm{mM} \mathrm{NaF}$, and $10 \mathrm{mM}$ ß-glycerophosphate]. Nuclear extract was collected by centrifugation at $18,000 \mathrm{x} \mathrm{g}$ for $5 \mathrm{~min}$.

Immunofluorescence. Cells were fixed in $70 \%$ methanol, $30 \%$ acetone for $15 \mathrm{~min}$ at $-20^{\circ} \mathrm{C}$ and blocked for $1 \mathrm{~h}$ in $4 \% \mathrm{BSA} /$ PBS, followed by incubation in primary antibody (1:100) for $1 \mathrm{~h}$ at room temperature. Cells were washed in PBS and incubated in secondary FITC-conjugated antibody (1:200) for $30 \mathrm{~min}$ at room temperature. Cells were washed with PBS and counterstained with DAPI.

\section{Results}

FBXO31 is expressed at low level in HCC specimens and cell lines. To investigate the expression profile of FBXO31, realtime RT-PCR was used to determine relative expression of FBXO31 in a panel of HCC cell lines. Results showed that FBXO31 was highly expressed in fetal liver and the fetal liver-derived cell line L02, but very low in the majority of HCC cell lines (Fig. 1A). The expression of FBXO31 was further evaluated in $32 \mathrm{HCC}$ specimens and adjacent healthy liver tissues by quantitative real-time RT-PCR. FBXO31 was down-regulated in 30/32 (93.75\%) HCC specimen tested compared to adjacent healthy liver tissues (Fig. 1B).

Alteration of FBXO31 expression effects growth of HCC cell lines. Since it was determined that expression of FBXO31 was lower in HCC specimens and cell lines, we investigated if this gene could function as a tumor suppressor. Ectopic expression of a tumor suppressor in a cancer cell line would be expected to inhibit the ability of cells to initiate colonies on plastic and inhibit cell proliferation. FBXO31 was ectopically expressed in the HCC cell lines HepG2 and Hep3B. Colony formation on plastic was assessed. Our data showed a reduction in colony formation, compared with the vector control, when transfected with FBXO31 (Fig. 2A and B). This reduction in colony formation averaged $35.4 \%$ for HEPG2 and 39.24\% for Hep3B from five independent experiments (Fig. 2C). The effect of FBXO31 ectopic expression on the proliferation was also determined by generating cultures of G418-resistant HEPG2 cells following FBXO31 transfection. Growth curves of these 
$24 \mathrm{~h}$

A
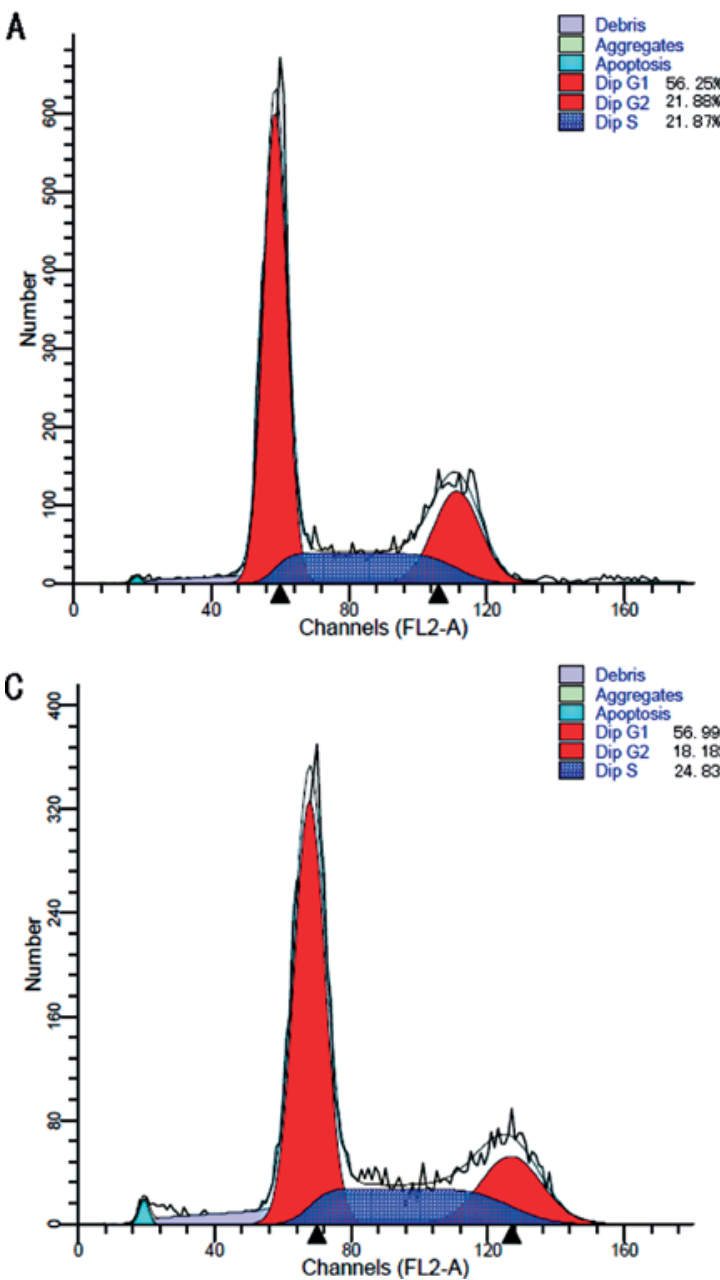

$48 \mathrm{~h}$

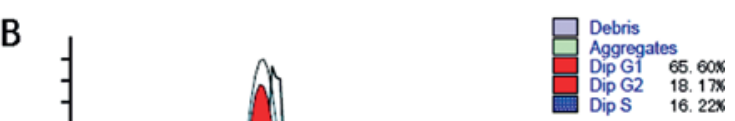

Figure 3. FBXO31 ectopic expression blocks cells at G0-G1 of the cell cycle. Cell cycle curves of EGFP-positive asynchronous HepG2 cultures 24 and 48 h after transfection with EGFP fusion constructs of FBXO31 (A and B) and empty vector (C and D).

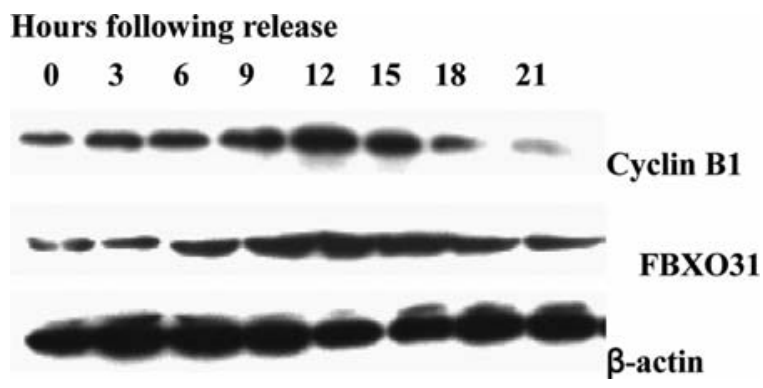

Figure 4. FBXO31 is cell cycle regulated in HepG2. HepG2 cells were synchronized with a double thymidine block, harvested at the indicated time-points after release from the block and analyzed by Western blot analysis. Blots were probed with anti-FBXO31, anti-cyclin B1 and antiB-actin.

cell lines showed that cells expressing FBXO31 had a reduction compared with the vector control (Fig. 2D).

FBXO31 is cell cycle regulated in HepG2. Following the findings that ectopic expression of FBXO31 suppressed growth, a fluorescence activated cell sorting-based cell cycle analysis was used to determine if the mechanism of this growth

\section{FBXO31 empty vector}

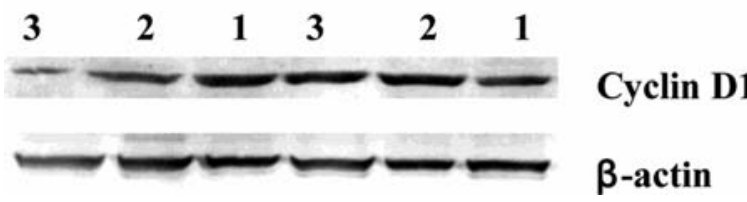

Figure 5. Cyclin D1 level decreases in cells transfected with myc-tagged FBXO31. HepG2 cells were transiently transfected with different concentrations (1-3 $\mu \mathrm{g})$ of myc-tagged FBXO31 or empty vector.

suppression is due to a specific effect on the cell cycle. Cell cycle analysis was done on the HCC cell line HEPG2 transiently expressing the EGFP- FBXO31 for 24 and $48 \mathrm{~h}$. Analysis of the asynchronous cell populations showed a $9 \%$ increase in the proportion of EGFP-FBXO31-expressing G1 cells from 24 to $48 \mathrm{~h}$ (Fig. $3 \mathrm{~A}$ and B) compared with the $3 \%$ increase observed in only EGFP-expressing G1 cells in the same time period (Fig. 3C and D). These observations suggest that a block in the cell cycle at G1 is the probable cause of the observed negative effect of FBXO31 ectopic expression on growth of the HCC cell line. 


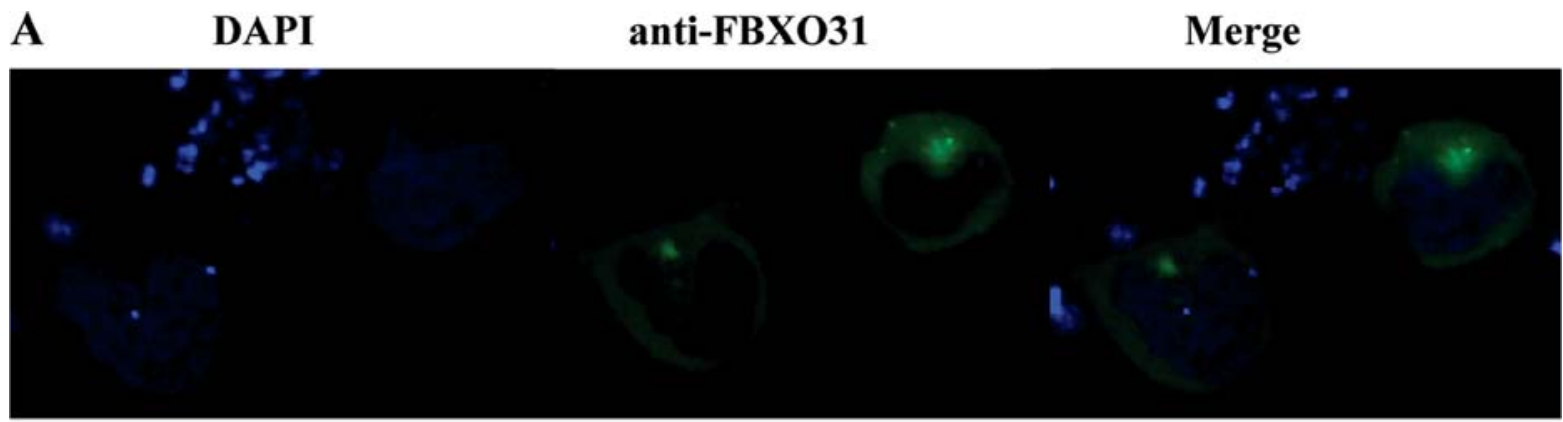

B

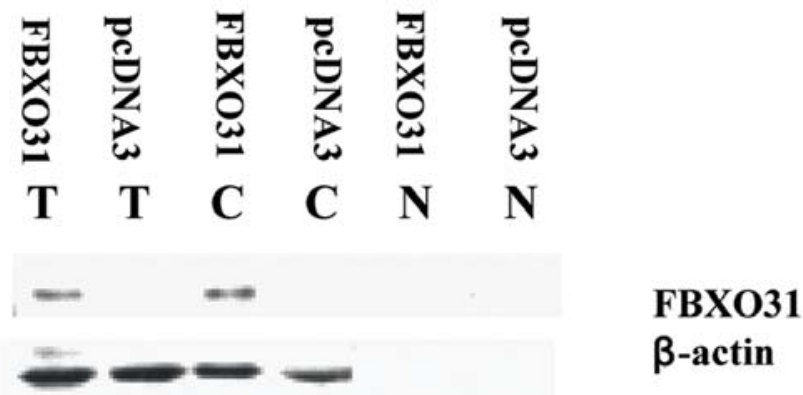

The cell cycle regulation of FBXO31 levels was then investigated. The endogenous FBXO31 levels were determined using an affinity-purified rabbit polyclonal anti-FBXO31 antibody. FBXO31 levels at different stages of the cell cycle were investigated in HEPG2 by collecting samples at various time points following release from a double thymidine block. The variation in levels of FBXO31 at different times after release of the block shows that this protein is cell cycle regulated. The cell cycle synchronization was confirmed by change in the levels of cyclin B1. These levels were maximal at 9-15 $\mathrm{h}$ for HEPG2. Cell progression from mitosis is associated with decreased levels of cyclin B1. The levels of FBXO31 were maximal from 9 to $18 \mathrm{~h}$ after release (Fig. 4). Comparison with the cyclin $\mathrm{B} 1$ cell cycle profile indicated that levels of FBXO31 protein were maximal at late G2 to early G1 phase.

Ectopic expression of FBXO31 results in cyclin D1 downregulation. Cyclin D1 is a well-documented important regulator that promotes the G1- to S-phase transition of cell cycle progression and functions as an oncogene involved in many cancers, including HCC $(13,14)$. FBXO31 mediates the degradation of cyclin D1 through a proteasome-directed pathway (10). We examined the expression of cyclin D1 in HepG2 cells that transiently transfected with different concentrations of myc-tagged FBXO31 or empty vector. Our data indicated that expression of cyclin D1 was decreased while it increased the expression of FBXO31 (Fig. 5).

Cyclin D1 ubiquitination and proteolysis are postulated cytoplasmic events, suggesting the involvement of a cytoplasmic E3 ligase. Immunofluorescence staining, utilizing specific FBXO31 antibodies, revealed cytoplasmic FBXO31 in HEPG2 cells (Fig. 6A). The cytoplasmic localization was confirmed by biochemical fractionation (Fig. 6B).

Figure 6. Cytoplasmic localization of FBXO31. (A) Immunofluorescence of asynchronously growing HepG2 cells with FBXO31-specific antibodies. (B) Stable HepG2 cells expressing empty vector or myc-tagged FBXO31 were fractionated into cytoplasmic $(\mathrm{C})$, nuclear $(\mathrm{N})$ and total $(\mathrm{T})$ extracts. Fractions were used for direct Western blots as indicated.

\section{Discussion}

FBXO31 belongs to the human F-box family consisting of three subfamilies and over 70 members. F-box containing proteins act as substrate recognition components of the SCF ubiquitin-ligase complexes in the ubiquitin-dependent proteasome degradation pathway. These complexes contain four components; Skp1, Cullin, Rbx-Rocl-Hrtl and an F-box protein (1-4). FBXO31 is associated with the Skp1, Roc-1 and Cullin-1 proteins through its substrate recognition domain and forms $\mathrm{SCF}^{\mathrm{FBXO} 11}$ ubiquitination complex (9).

F-box proteins regulate protein abundance and the function of oncogenes, tumor suppressors, transcription factors and other signaling molecules via ubiquitin-dependent proteasome degradation pathway. Some F-box proteins act like oncogenes or tumor suppressors. Skp2 is the product of a protooncogene and overexpressed in many tumors. $\mathrm{SCF}^{\mathrm{Skp} 2}$ targets tumor suppressor gene products and CDK inhibitors such as p130, Tob1, p27(Kip1), p57(Kip2), and p21(Cip1) (15-22). In contrast, degradation of several oncogene products, such as Cyclin E, Notch, c-Myc, c-Jun, and c-Myb, are mediated by $\mathrm{SCF}^{\mathrm{Fbw}} 7$ (23-28). Fbw7 is often deleted or mutated in human cancers and acts like a tumor suppressor. FBXO31 is a potential tumor suppressor shown to be down-regulated in breast cancer cell lines relative to normal breast expression. FBXO31 mediated Cyclin D1 degradation to induce G1 arrest after DNA damage.

The expression profile of FBXO31 was still unclear except for breast cancer. We examined the expression profile of FBXO31 in lung tumor and HCC samples. FBXO31 was down-regulated in $65 \%$ of lung tumor samples (data not shown) and $93.75 \%$ of HCC samples (Fig. 1). We decided to investigate mechanisms relevant to down-regulation of FBXO31 in HCC. A previous study (9) proved FBXO31 was 
a candidate breast tumor suppressor. Therefore, the possibility was investigated that FBXO31 may function as a tumor suppressor in HCC. Ectopic expression of a tumor suppressor in a cancer cell line would be expected to inhibit the ability of cells to initiate colonies on plastic and inhibit cell proliferation. Our data indicated that ectopic expression of FBXO31 resulted in a moderate inhibition of colony growth on plastic and reduced the proliferation of HEPG2 cells, which was consistent with the tumor suppressor properties (Fig. 2). It has been reported that ectopic expression of FBXO31 induced senescence in breast cancer cell line MCF-7. We failed to detect senescence in HEPG2 cells (data not shown).

Then we investigated the possibility that the tumor suppressor effect was cell cycle related. Investigation of endogenous FBXO31 expression in synchronized HEPG2 cells showed FBXO31 protein levels were maximal from late G2 to early G1 phase (Fig. 4). The timing of FBXO31 destruction was consistent with APC-mediated degradation. Cell cycle analysis of the HCC cell line ectopically expressing FBXO31 was performed. We observed a block in the cell cycle at G1 (Fig. 3). There might be a possibility that inhibition of growth of HCC cell line by ectopic FBXO31 expression was caused by cells not progressing normally past G1 phase of the cell cycle. This conclusion was further supported by the fact that FBXO31 acted through a proteasome-directed pathway to mediate the degradation of cyclin D1, an important regulator of progression from G1 to $\mathrm{S}$ phase, resulting in arrest in G1 (10). Our data showed ectopic expression of FBXO31 in HepG2 could lead to down-regulation of Cyclin D1 (Fig. 5). Cytoplasmic location of FBXO31 in HepG2 was consistent with the theory that Cyclin D1 ubiquitination and proteolysis were postulated cytoplasmic events (Fig. 6). In summary, the expression and functional studies of FBXO31 in the cell cycle were consistent with the properties of tumor suppressor. FBXO31 might function as a tumor suppressor in HCC.

The tumor suppressor effect likely does not involve only a single gene. Team work is required to keep pace with cell growth. Though we reported FBXO31 might function as a tumor suppressor in $\mathrm{HCC}$, further investigation needs to be done to uncover the complexity of $\mathrm{FBXO} 31$ tumor suppressor effect on HCC.

\section{Acknowledgements}

This work was funded by Science Project of the Key Lab of Guangdong province and the International Collaboration Project of Guangzhou City. We thank Dr Xiao-chun Bai (Department of Cell Biology, Southern Medical University, Guangzhou, China) for useful discussion.

\section{References}

1. Bai C, Sen P, Hofmann K, Ma L, Goebl M, Harper JW and Elledge SJ: SKP1 connects cell cycle regulators to the ubiquitin proteolysis machinery through a novel motif, the F-box. Cell 86: 263-274, 1996

2. Hochstrasser M: Ubiquitin-dependent protein degradation. Annu Rev Genet 30: 405-439, 1996.

3. Skowyra D, Craig KL, Tyers M, Elledge SJ and Harper JW: F-box proteins are receptors that recruit phosphorylated substrates to the SCF ubiquitin-ligase complex. Cell 91: 209-219, 1997.

4. Ho MS, Tsai PI and Chien CT: F-box proteins: the key to protein degradation. J Biomed Sci 13: 181-191, 2006.
5. Winston JT, Koepp DM, Zhu C, Elledge SJ and Harper JW: A family of mammalian F-box proteins. Curr Biol 9: 1180-1182, 1996.

6. Cenciarelli C, Chiaur DS, Guardavaccaro D, Parks W, Vidal M and Pagano M: Identification of a family of human F-box proteins. Curr Biol 9: 1177-1179, 1999.

7. Jin J, Cardozo T, Lovering RC, Elledge SJ, Pagano M and Harper JW: Systematic analysis and nomenclature of mammalian F-box proteins. Genes Dev 18: 2573-2580, 2004.

8. Kipreos ET and Pagano M: The F-box protein family. Genome Biol 1: Reviews3002, 2000.

9. Kumar R, Neilsen PM, Crawford J, et al: FBXO31 is the chromosome 16q24.3 senescence gene, a candidate breast tumor suppressor, and a component of an SCF complex. Cancer Res 65: 11304-11313, 2005.

10. Santra MK, Wajapeyee N and Green MR: F-box protein FBXO31 mediates cyclin D1 degradation to induce G1 arrest after DNA damage. Nature 459: 722-725, 2009.

11. Wang ZC, Lin M, Wei LJ, Li C, Miron A, Lodeiro G, Harris L, Ramaswamy S, Tanenbaum DM, Meyerson M, Iglehart JD and Richardson A: Loss of heterozygosity and its correlation with expression profiles in subclasses of invasive breast cancers. Cancer Res 64: 64-71, 2004.

12. Bais AJ: FBXO31 (F-box protein 31). Atlas Genet Cytogenet Oncol Haematol, June 2008. URL: http://AtlasGenetics Oncology.org/Genes/FBXO31ID44280ch16q24.html

13. Resnitzky D, Gossen M, Bujard H and Reed SI: Acceleration of the G1/S phase transition by expression of cyclins D1 and E with an inducible system. Mol Cell Biol 14: 1669-1679, 1994.

14. Diehl JA, Cheng M, Roussel MF and Sherr CJ: Glycogen synthase kinase-3beta regulates cyclin D1 proteolysis and subcellular localization. Genes Dev 12: 3499-3511, 1998.

15. Nakayama K, Nagahama H, Minamishima YA, et al: Targeted disruption of Skp2 results in accumulation of cyclin $\mathrm{E}$ and p27Kip1, polyploidy and centrosome overduplication. EMBO J 19: 2069-2081,2000

16. Ganoth D, Bornstein G, Ko TK, et al: The cell-cycle regulatory protein Cks1 is required for SCFSkp2-mediated ubiquitinylation of p27. Nat Cell Biol 3: 321-324, 2001.

17. Kamura T, Hara T, Kotoshiba S, et al: Degradation of p57Kip2

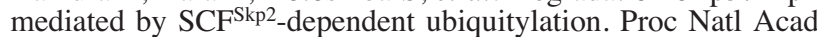
Sci USA 100: 10231-10236, 2003.

18. Tedesco D, Lukas J and Reed SI: The pRb-related protein p130 is regulated by phosphorylation-dependent proteolysis via the protein-ubiquitin ligase SCFSkp2. Genes Dev 16: 2946-2957, 2002.

19. Hiramatsu Y, Kitagawa K, Suzuki T, et al: Degradation of Tob1 mediated by SCFSkp2-dependent ubiquitination. Cancer Res 66: 8477-8483, 2006.

20. von der Lehr N, Johansson S, Wu S, et al: The F-box protein Skp2 participates in c-Myc proteosomal degradation and acts as a cofactor for c-Myc-regulated transcription. Mol Cell 11: 1189-1200, 2003

21. Imaki H, Nakayama K, Delehouzee S, et al: Cell cycle-dependent regulation of the Skp2 promoter by GA-binding protein. Cancer Res 63: 4607-4613, 2003.

22. Yokoi S, Yasui K, Saito-Ohara F, et al: A novel target gene, SKP2, within the $5 \mathrm{p} 13$ amplicon that is frequently detected in small cell lung cancers. Am J Pathol 161: 207-216, 2002.

23. Kanei-Ishii C, Nomura T, Takagi T, Watanabe N, Nakayama KI and Ishii S: Fbxw7 acts as an E3 ubiquitin ligase that targets c-Myb for nemo-like kinase (NLK)-induced degradation. J Biol Chem 283: 30540-30548, 2008.

24. Kitagawa K, Hiramatsu Y, Uchida C, et al: Fbw7 promotes ubiquitin-dependent degradation of c-Myb: involvement of GSK3-mediated phosphorylation of Thr-572 in mouse c-Myb. Oncogene 28: 2393-2405, 2009.

25. Wu G, Lyapina S, Das I, et al: SEL-10 is an inhibitor of notch signaling that targets notch for ubiquitin-mediated protein degradation. Mol Cell Biol 21: 7403-7415, 2001.

26. Mao JH, Kim IJ, Wu D, et al: FBXW7 targets mTOR for degradation and cooperates with PTEN in tumor suppression. Science 321: 1499-1502, 2008.

27. Thompson BJ, Buonamici S, Sulis ML, et al: The $\mathrm{SCF}^{\mathrm{FBW} 7}$ ubiquitin ligase complex as a tumor suppressor in T cell leukemia. J Exp Med 204: 1825-1835, 2007.

28. Onoyama I, Tsunematsu R, Matsumoto A, et al: Conditional inactivation of Fbxw7 impairs cell-cycle exit during $\mathrm{T}$ cell differentiation and results in lymphomatogenesis. J Exp Med 204: 2875-2888, 2007. 